Association for Information Systems AIS Electronic Library (AISeL)

Wirtschaftsinformatik Proceedings 2001

Wirtschaftsinformatik

September 2001

\title{
E-Health: Towards a Bright Future
}

Rainer Salfeld

McKinseyぬ Company, rainer_salfeld@mckinsey.com

Follow this and additional works at: http://aisel.aisnet.org/wi2001

\section{Recommended Citation}

Salfeld, Rainer, "E-Health: Towards a Bright Future" (2001). Wirtschaftsinformatik Proceedings 2001. 60.

http://aisel.aisnet.org/wi2001/60

This material is brought to you by the Wirtschaftsinformatik at AIS Electronic Library (AISeL). It has been accepted for inclusion in Wirtschaftsinformatik Proceedings 2001 by an authorized administrator of AIS Electronic Library (AISeL). For more information, please contact elibrary@aisnet.org. 
In: Buhl, Hans Ulrich, u.a. (Hg.) 2001. Information Age Economy; 5. Internationale Tagung Wirtschaftsinformatik 2001. Heidelberg: Physica-Verlag

ISBN: 3-7908-1427-X

(C) Physica-Verlag Heidelberg 2001 


\title{
E-Health: Towards a Bright Future
}

\author{
Rainer Salfeld \\ McKinsey \& Company
}

E-Health is certainly one of the most exciting businesses in the New Economy. EHealth uses new IT \& Communication technologies to optimize management of health services both within and between service providers.

There are three reasons for this: E-Health promises clear improvements for all participants in our health care systems: providers, patients and payors. It has real economic significance, given the size of the health care markets and the economic value that can be captured. And finally it offers great opportunities to advance the state of the art in IT by taking on the challenges of E-Health.

\section{Expected Advances in Health Care Service Provision}

We are at the beginning of a decade in which new technologies will fundamentally revolutionize health care systems as we know them. In all industrialized countries, these systems represent the largest single markets, with expenditures ranging from 8 to $14 \%$ of their gross national product. In Germany for instance, the annual spendings on health care are well in excess of 500 billion DM. Every eighth DM we spend in Germany goes to health care.

Accordingly, IT costs for providing health care services are staggering too. In the German public health care sector alone, they probabely add up to about 5 to 6 billion DM - although IT solutions sofar have only been used for a limited range of tasks. Currently, they are used to support administrative tasks rather than therapeutic needs.

What makes health care ripe for an e-health revolution are two obvious inefficiencies: (1) old-fashioned paper based processes that still dominate the internal operations of all service providers and payors as well; (2) an extremely fragmented service provider landscape. These two factors combined make the whole sector look like an ideal candidate for E-Health applications

However, the causes for the current inefficiencies also present significant hurdles that need to be overcome: One is the high level of regulation that impedes neces- 
sary changes. The other is the fact that many service providers are non-profit organizations.

We therefore have to realize what a keen observer was commenting on when he said:"Whereas fantasy raised the spirits of investors just 12 months ago, many enthusiasts are now beginning to realize that changes in the health systems will come - although slower than expected, and at a higher price.

Nevertheless: E-Health will bring about long-term change in at least the following areas.

\subsection{Substituting Paper Based Processes}

E-Health can standardize and increase the efficiency and effectiveness of communication between physicians, hospitals, health insurers, pharmacies, laboratories and patients. At least that is what E-Health propaganda is saying.

E-Health is not only expected to eliminate obsolete administrative tasks but also to increase the speed and precision of information. For the first time, networked systems will give the physician in charge fast access to the patient's medical history from both Internet terminals and wireless technology. By medical history I mean the complete medical records on a patient not just the individual notes of the physician himself - as has been the case up to now.

This will do away with the usual mass of paper documentation that is often riddled with mistakes. Quite a lot of it is still hand-written: prescriptions, claims, physician letters, settlement statements etc.

Instead, there will be one simple and consistent net-based system that will provide everyone involved with a complete set of information.

\subsection{Integrating Service Providers}

It seems perfectly feasible to link physicians, hospitals, laboratories and health insurers via the Internet - without creating enormous cost increases.

First, however, we need to learn to walk before we try to run.

Let's do a reality check! Over three quarters of the roughly 130.000 non-hospital based physicians work in individual practices. For this group in particular, netbased applications could offer the desired integration necessary to provide a comprehensive, holistic treatment process. Two thirds of these practices have a PC system installed, but only about $30 \%$ at most have an Internet connection, too. 
Moreover, there is another problem - the mental barrier that many physicians have put up. Physicians are primarily concerned with treating patients, in perfect accordance with their professional role, background and mindset. They do not have time to spend on integrating their practices into a holistic system of service provision.

The IT- situation in hospitals is somewhat different, but not really satisfactory either: In hospitals, IT is mainly used by the administrative staff and usually for administative purposes. It is only rarely used on-site, to support doctors and nurses carrying out their daily jobs.

Some individual hospitals, however, do have completely integrated, electronic patient records that can be accessed by physicians and nurses treating or attending patients. Electronic transfer of claims and automatic linking of calculation functionalities also exist. However, the use of such systems as standard practice is still a long way off.

If its is so difficult to implement systems like these within a single hospital, then it is without doubt infinitely more difficult to integrate physicians, pharmacies, external laboratories and health insurance companies into one holistic nationwide system.

All the more so, as there is precious little public funding available. All federal states with the exception of Bavaria are struggling to finance the upkeep of their hospitals. Increasingly unable to afford the paint on their walls, many hospitals simply lack the financial means to invest in complex E-Health systems.

So, both patience and persistence will be needed until an E-Health based health care system can be established. This is not only true for hospitals and physicians, but also for other participants like sickness funds, pharma manufacturers and insurance companies.

\section{Capturing the Economic Value}

Start-up companies were the first to introduce E-Health solutions, with the intention of tapping the huge economic potential of this market. They were also able to receive generous funding from the capital markets.

Dr. C. Everett Koop, the former US Surgeon General, became one of the first Internet multi-millionaires with his website dr.koop.com. In fact, he made it to the top 50 young entrepreneurs in the Internet edition of the TIME MAGAZINE - at the venerable age of 82 .

With the evaporation of the stock market euphoria, E-Health stock fared even worse than other Internet stock. Its value has decreased by a disproportionately 
high amount. The fortunes of WebMD corporation are fairly typical: A pioneer in E-Health with over 2000 employees, this US dot.com saw its share price peak at 105 USD in May 2001 and then tumble to a low of 7 USD in this May. Nevertheless, WebMD was relatively lucky - compared to Planet RX for example. This market leader in retailing health and beauty products imploded totally; its share price fell from about 26 USD at the end of 1999 to 28 cents as of today. Its management can hardly be held to blame for this, as the company had developed as planned.

Obviously, the markets are no longer willing to believe that companies like these will break even in the short term and are therefore cutting back on the amount of capital available to them.

As a consequence, the responsibility for building and expanding the E-Health-business has shifted to larger, well-established companies - in particular to statutory sickness funds and health insurance companies. With fairly deep pockets, these incumbents can muster all the resources and assets required. Following on the heels of the pioneers they also can draw on the lessons the pioneers had to learn in the hard way.

Sooner rather than later the incumbents will play a pivotal role in designing the Internet based E-Health system. Two examples illustrate this clearly:

The Kassenärztliche Vereinigung Bayern, which manages more than 20.000 physicians, has decided to build an extranet that will serve as a platform for all administrative interactions between the $K V B$ and its physicians. Of course, this extranet will also be a suitable platform for the exchange of therapeutic data in the long run.

Another example is Medvantis, a disease management service provider, founded by $D B V$ Winterthur Versicherung. With investments of more than 70 million DM in the first 24 months, Medvantis has made huge strides in setting up an E-Health platform that will serve a large number of private insurers and public sickness funds.

\section{Taking on the IT-Challenges}

Technology has been the catalyst at the beginning of the E-Health revolution and it will continue to play a key role in the future.

Today's IT solutions are not sufficiently advanced to cater to the needs of the new E-Health world. Science will need to progress quickly to permit the easy integration of providers and technologies. Some of the challenges that need to be addressed by the IT communities include: 
Development of work flow-based systems to integrate processes across different service providers It appears to be worth emulating the whole chain of medical service provision - seamlessly, with no need to switch the media used. In addition, all service providers involved in the process should be properly integrated, thus ensuring maximum process efficiency and output transparency.

Setting clear standards for patient and medical data processing: Socio-medical data ought to be continuously and comprehensively gathered, analyzed, structured and provided to the public in sanitized form. In this way, the flow of data will not only support administrative processes, but also significantly contribute to improvements in therapeutical procedures and clinical research. Special emphasis should therefore be placed on maximum standardization of those meta-identifiers that are used to describe the given data. To achieve this, the use of basic technologies such as XML XLS and DTD should be vastly expanded. A key challenge will be to drive this standardization process across such a heterogeneous set of stakeholders.

Integration of channels: Multiple communications channels (including mobile) should be integrated as a top priority, since they are esssential for the success of EHealth applications. Also, call center technologies should be given high priority.

Migration to new technology platforms: Large portions of today's IT spendings are still allocated to large monolithic, host-based architectures as operated by public sickness funds, the Kassenärztliche Vereinigungen and private payors. Therefore it would be rewarding to (re)consider how the ongoing migration to multi-tier architectures can be best managed in order to provide a seamless integration into future E-Health systems.

It will be a tremendous challenge for everyone in the IT community to address the issues mentioned above and moreover the many others that exist. However, the goal of fundamentally restructuring the largest sector in the economy of industrialized nations is clearly worth the effort. It will allow for health care systems that have higher therapeutical standards, at achievable costs.

In Germany, it will, at the end of the day, provide us with a health care system we can be proud of. It will certainly do much better than our current one ranked only $25^{\text {th }}$ on the WHO ranking list. 